\title{
LA CANDIDATURA A LA PRESIDENCIA DEL GOBIERNO EN ESPAÑA: LOS CASOS DEL PP Y DEL PSOE EN LAS ELECCIONES GENERALES DE 2004*
}

\author{
Presidential Candidates in Spain: the Cases of PP and PSOE \\ in the 2004 General Election
}

\section{SANTIAGO DELGADO FERNÁNDEZ}

Universidad de Granada

\begin{abstract}
RESUMEN
Este trabajo describe y analiza los procesos formales e informales de selección utilizados por el Partido Popular y por el Partido Socialista Obrero Español para determinar el nombre de quién habría de encabezar la candidatura a la Presidencia del Gobierno de España en las elecciones de marzo de 2004. La comparación nos permite afirmar que, pese a prever formas distintas en ambos casos, se dio un bajo nivel real de inclusión democrática. Para preservar la cohesión interna y fortalecer el liderazgo de los partidos se optó por el centralismo en la toma de decisiones, por la eliminación de una competencia efectiva entre candidatos y por la reducción del número de los participantes en la selección.
\end{abstract}

Palabras clave: España, candidatos, inclusión democrática, cohesión democrática, liderazgo.

\begin{abstract}
This article describes and analyzes the formal and informal processes of selection used by the Popular Party and by the Socialist Spanish Party in order to determine the person who would be the candidate to the Presidency of the Government of Spain in the elections of March 2004. The comparison allows us to state that, in spite of foreseeing different forms, in both cases a low level of internal party participation was found. To preserve the internal cohesion and to strengthen the leadership of parties, three approaches were taken: the centralization of decision making, the elimination of effective competition between candidates and reduction of the number of the participants in the selection process.
\end{abstract}

Key words: Spain, candidates, democratic inclusion, democratic cohesion, leadership.

\section{INTRODUCCIÓN}

La costumbre, extendida en casi todos los partidos, de elegir a su máximo dirigente y líder como candidato a la Presidencia del Gobierno convirtiéndolo en una imagen de marca, así como la simplificación del escenario político electoral que los medios de comunicación de masas precisan en aras de la espectacularización de la política, han

* Mi agradecimiento a Rafael Estrella Pedrola, actual embajador de España en Argentina, por la ayuda prestada para acceder a una parte significativa de las fuentes empleadas, y al profesor Antonio Robles Egea, por "escuchar" y hacerme sugerencias siempre pertinentes. 
contribuido a desvirtuar el procedimiento parlamentario previsto constitucionalmente para el nombramiento del Presidente del Gobierno en España. ${ }^{1}$ En la práctica, aquél ha sido sustituido en el imaginario colectivo por una presidencialización de hecho. Así, con ocasión de las elecciones generales, la mayor parte de los electores piensan al emitir su voto que están eligiendo al futuro presidente de Gobierno, y no a los diputados de su circunscripción, sobre quienes realmente recae la responsabilidad de otorgar la confianza a quien proponga el Rey. ${ }^{2}$

A fomentar este equívoco, que duda cabe, también ha contribuido el carácter racionalizado del parlamentarismo español. Para preservar la estabilidad del sistema, los constituyentes del 78, siguiendo el ejemplo de los países del entorno europeo, reforzaron al ejecutivo y, por tanto, a su presidente, frente al legislativo. El efecto ha sido la aparición de un ejecutivo predominante y firme en el cual el presidente ocupa un lugar destacado. A él le corresponde enfrentarse al parlamento para ser investido y elaborar el discurso programático para, una vez nombrado, ser responsable de elegir a los ministros que formarán parte de su Gobierno. En definitiva, el presidente ha ido asumiendo, a tenor del papel constitucional atribuido, un protagonismo inusitado en la vida política que lo termina convirtiendo, no sólo en el jefe de la mayoría parlamentaria de turno, sino también, casi siempre, en el máximo dirigente del aparato político de su propio partido y en el referente político central para los ciudadanos (Montabes, 2001: 172-174).

Pues bien, una de las consecuencias políticas de la presidencialización de hecho del sistema ha sido que los principales partidos españoles reservan apartados de sus normas internas para concretar las fórmulas empleadas en la determinación del nombre de quien, llegado el caso, será propuesto a la investidura como Presidente del Gobierno. ${ }^{3}$ Han caído en la cuenta de que, en buena medida, de la capacidad que tenga el procedimiento previsto para elegir al candidato idóneo dependerá la suerte electoral del partido.

En las elecciones generales de marzo de 2004, por vez primera en los veinticinco años de andadura democrática desde la aprobación de la Constitución de 1978, los dos principales partidos de ámbito estatal tuvieron que presentar un candidato nuevo. El Partido Socialista Obrero Español (PSOE), después de al menos dos frustrados intentos de consolidar un liderazgo y tras la pérdida de dos elecciones; el Partido Popular (PP), abocado a nominar un candidato en sustitución de José María Aznar, quien en 2001, respetando un compromiso electoral asumido años antes, confirmó su renuncia a ser cabeza de cartel en las siguientes elecciones generales.

$1 \quad$ El fenómeno consistente en considerar a los candidatos como una imagen de marca que compiten por lograr la atención de los clientes/votantes en el mercado del info-entretenimiento recibe el nombre de political branding. Conscientes del papel de los medios de comunicación de masas, los partidos políticos eligen a sus candidatos políticos y, más concretamente a los candidatos a la presidencia del Gobierno, "sobre la base de sus superiores capacidades para utilizar los [citados] medios". (Manin, 1992: 92).

2 El artículo 99 de la Constitución española establece el procedimiento a seguir para el nombramiento del presidente del Gobierno. Según el tenor de dicho artículo, le corresponde al Rey después de que el Congreso de los Diputados, por el voto de la mayoría absoluta de sus miembros, otorgue su confianza al candidato.

3 Pese a que la Constitución reconoce el derecho del ciudadano a la participación activa y pasiva, son los partidos quienes realmente tienen la tarea de concretar a los "elegibles", mediante su incorporación en candidaturas. Así ocurre también para el caso de la persona que, llegado el caso, presentarán como su opción a la Presidencia del Gobierno. 
En este artículo, mediante la descripción y análisis de los procesos formales e informales de selección utilizados por el PP y por el PSOE, se ponen al descubierto las similitudes y diferencias entre los mecanismos de cada partido, así como el bajo grado de inclusión democrática logrado a consecuencia de la prioridad de los objetivos de cohesión intrapartidista. ${ }^{4}$ Partiendo de la consideración de los partidos como organizaciones que disponen de una estructura triangular -afiliados, cargos orgánicos y cargos electos-, esta vez vamos a privilegiar en el estudio de la inclusión democrática, como una de las caras de la democracia interna, a los mecanismos de selección de candidatos frente a los tradicionales análisis relativos a los niveles de control sobre los órganos directivos de los partidos por parte de los afiliados.

Más allá de las diferencias formales entre uno y otro partido, advertiremos que en ambos existieron pocas posibilidades de concurrir como candidato al margen de los designios de las respectivas direcciones. Además, se comprobará cómo, llegado el momento, los militantes tuvieron una participación muy reducida en la selección del candidato, existiendo un considerable grado de intervención, en el caso del PP, especialmente protagonizada por el líder saliente; en el caso del PSOE, atribuible a la dirección nacional previo acuerdo de los líderes-barones territoriales. ${ }^{5}$

El trabajo se divide en tres bloques. En el primero se lleva a cabo una aproximación a las fórmulas de selección de candidatos en el derecho y la ciencia política comparada, al tiempo que se enumeran algunos de los requisitos legales exigibles y que, por lo tanto, los partidos deben considerar a la hora de nominar a su candidato. Además, se abordan las reglas formales que el PSOE y el PP tuvieron que observar para la nominación de los candidatos a la Presidencia del Gobierno en el 2004, y se responde a lo previsto en los estatutos y demás normas internas sobre el perfil de las personas que podían ser elegidas -los candidatos- y las que ostentaban la responsabilidad de hacer la elección en uno y otro partido. Por último, dentro también de este primer bloque, se concretan las fases previstas en cada partido para fijar el nombre de su candidato. En un segundo epígrafe se analizan los procesos reales seguidos en el seno del PSOE y del PP para mostrar la intrahistoria procesal y sacar a la luz los elementos contextuales, las motivaciones de los actores y los criterios de selección empleados. Comparando lo formal con lo real, se hará más visible la verdadera naturaleza del comportamiento de los partidos. Por último, se esbozan algunas reflexiones en torno al grado de inclusión democrática interna y cohesión lograda por los procesos expuestos.

4 El grado de inclusión democrática dependerá de la mayor o menor extensión tanto de la "población" participante en el proceso selectivo de los concurrentes a la presidencia como del número de estos últimos. Este concepto de inclusión lo extraemos de una interpretación de la "ciudadanía inclusiva" a la que se refiere Robert Dahl. (Dahl, 1999: 100). Por su parte, el objetivo de la cohesión interna será directamente proporcional al grado de inclusión; esto es, a mayor inclusión, menor cohesión (Rahat y Hazan, 2001: 314).

5 Aunque no es el objeto concreto de este trabajo, los comportamientos aquí descritos entroncan con la literatura existente sobre el comportamiento oligárquico de los partidos políticos de autores como Pareto, Mosca, Michels, Von Beyme, Panebianco, Sartori, etc. 


\section{PROCEDIMIENTOS FORMALES}

En política comparada, atendiendo a quién corresponde la fijación de las normas para seleccionar a cualquier candidato, incluido el que concurre a la Presidencia del Gobierno, son tres los grandes modelos formales empleados. Por un lado, el de competencia exclusiva de partido. Por otro, el de tutela básica estatal con fijación de condiciones mínimas a seguir por los partidos en sus procesos de selección de candidatos y, por último, el de participación estatal directa. En relación con estos modelos, y sobre la mayor o menor relevancia en la elección de unos u otros para la implantación de una democracia efectiva en el interior de los partidos, existen tres enfoques. De una parte, el modelo alemán, defensor de la intervención estatal para defender una vida interna democrática. Por otro lado, el modelo italiano que cree peligrosa toda injerencia pública y, en último lugar, los que no rechazan un determinado grado de regulación estatal, pero no tienen excesiva esperanza en la posibilidad de regular legalmente un fenómeno que es en esencia político (Barrat i Esteve, 1995: 95).

En España, pese a que la referencia constitucional a la obligatoriedad de una estructura y funcionamiento democráticos de los partidos supone una cierta intervención estatal en la determinación de las fórmulas de selección interna de los candidatos en general, no existe interferencia alguna en relación con el proceso de concreción de las candidaturas a la Presidencia del Gobierno. Ocurre de este modo, en tanto que el carácter parlamentario del sistema político impide que se puedan hacer previsiones sobre lo no advertido constitucional ni legalmente. No obstante, los partidos, como protagonistas y cauces fundamentales de la participación política, deberán observar en la fijación de los procedimientos internos para la selección del presidenciable, como si de otra cualquier candidatura se tratase, las disposiciones establecidas en relación con la obligatoriedad de una organización, un funcionamiento y una actividad democráticos, de acuerdo con lo dispuesto en la Constitución y en las leyes. ${ }^{6}$ De igual forma, quienes opten a la candidatura estarán obligados a cumplir una serie de requisitos fijados tanto en la propia Constitución y en la Ley de Régimen Electoral General como en la Ley de Gobierno. ${ }^{7}$ Así, por un lado, tendrán que disfrutar de los derechos de sufragio activo y pasivo, para lo que deberán ser españoles, mayores de edad, y estar inscritos en el censo electoral. Por otro, no podrán estar inhabilitados para ejercer empleo o cargo público por sentencia judicial firme. ${ }^{8}$

Si reparamos en quiénes pueden participar en el proceso de selección de los candidatos que afrontan los partidos, con distinto nivel de tutelaje estatal, existen también varias posibilidades que clasificaremos de mayor a menor grado en relación con su nivel de

6 Artículo 5 de la Constitución de 1978, artículo 2 de la LOREG, 5/1985, de 19 de junio, y artículos 6 y 7 de la Ley Orgánica de Partidos Políticos, 6/2002, de 27 de junio, BOE. núm. 154, de 28-05-2002.

7 Hacer uso del derecho de sufragio pasivo dependerá, en cualquier caso, de que la persona que lo posee sea presentada como candidata en el seno de una lista de las organizaciones o, en su caso, agrupaciones habilitadas legalmente para ello. Así, de conformidad con el tenor del artículo 44 de la LOREG, serán los partidos, federaciones, coaliciones y agrupaciones de electores inscritas en el registro que corresponda, quienes podrán presentar candidatos o listas de candidatos.

8 Artículos 11, 12, 13 y 23 de la Constitución española de 1977, y artículo 11 de la Ley de Gobierno, 50/1997, de 27 de noviembre. 
inclusión y de menor a mayor en cuanto al grado de cohesión que logran en el seno del partido. Así, nos encontramos con: primarias abiertas, primarias cerradas, eleccióndesignación por una convención o por el líder o líderes del partido en forma de órgano colegiado. La primera modalidad de primarias constituye un procedimiento de elección del candidato en el que participan todos los electores, siguiendo, en todo caso, una serie de pasos obligados, entre los que destaca la inscripción previa en un censo. En cuanto a las primarias cerradas, se trata de un proceder electivo en el que sólo toman parte los afiliados del partido de que se trate. ${ }^{9}$ La elección por una convención formada por una determinada cantidad de delegados partidarios supone una fórmula de designación de candidatos, algo menos restrictiva que la designación por el líder, fórmula esta última que sólo tiene en cuenta en la decisión final la consideración cuasi-exclusiva del parecer y voluntad de aquél. A veces, sin embargo, la decisión del líder se somete a ratificación de un órgano colegiado en el que están presentes otros dirigentes del partido, con la pretensión de suavizar una imagen excesivamente rígida y personalista del proceder. ${ }^{10}$

Por su parte, los modelos procesales de selección se pueden clasificar en función del nivel de inclusión de quién o quiénes pueden ser candidatos y del grado de cohesión que traigan aparejados unos y otros; todo ello, igualmente, al margen del distinto nivel intervención estatal. A grandes rasgos, se distinguen tres modelos ordenados de mayor a menor en relación a la inclusión, y de menor a mayor en cuanto al grado de cohesión. En primer lugar, el que permite la candidatura de cualquier ciudadano. En segundo término, el que sólo deja la posibilidad a los miembros del partido y, por último, el que acepta la participación de los miembros del partido, con determinadas condiciones o requisitos. Sin embargo, estos modelos resultan insuficientes para conocer el grado de inclusión en tanto no tienen en cuenta si los candidatos se pueden autoproponer, deben ser propuestos por otras personas miembros del partido, o bien por órganos colegiados de aquél. Esta circunstancia vendría a matizar los niveles de inclusión democrática de los tipos descritos.

En 2004, las modalidades procesales elegidas por el PSOE y por el PP fueron unas primarias cerradas que no se llegaron a desarrollar de forma competitiva por la concurrencia de un solo candidato, y un proceso designativo del líder, respectivamente. Sea como fuere, más allá de los mínimos prescritos por la Constitución y las leyes, cada partido podía fijar una serie de restricciones o limitaciones de partida para quien pretendiera acceder a la condición de candidato a la presidencia y para los potenciales participantes, en su caso, en los procesos internos o externos: afiliación o militancia del candidato y/o del elector, antigüedad en la misma, inscripción en un registro para poder tener derecho al voto, experiencia política previa del candidato, elaboración de una propuesta programática por el postulante, etc. Las mayores restricciones se fijaron por parte del PSOE y del PP con relación a los participantes en la elección: inscripción, tiempo de afiliación previa, pago de

9 Sobre las distintas modalidades de primarias véase (Salazar Benítez, 1999: 344-354).

10 Una clasificación de los métodos de selección de candidatos más comunes puede verse en (Rahat y Hazan, 2001: 297-322). De igual forma, véase (Gallagher y Marsch, 1988) y (Freidenberg y Sánchez, 2002: 321-361). No obstante, ha de advertirse que en general estos métodos se describen para el caso de sistemas presidencialistas. Por este motivo, su aplicabilidad al caso español debe considerarse como una licencia metodológica que, no obstante, resulta igualmente útil aplicable al sistema parlamentario español. 
Tabla 1: Modelos formales para la selección de candidatos

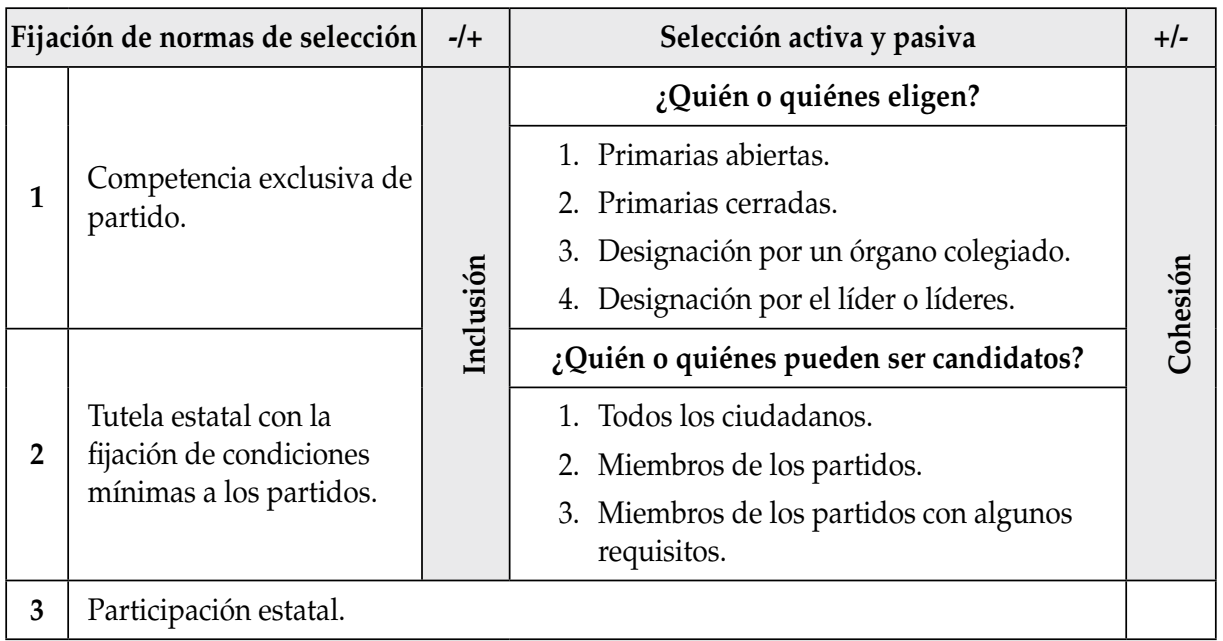

Fuente: elaboración propia a partir de la información contenida en (Barrat i Esteve, 1995: 95), (Rahat y Hazan, 2001: 301) y (Freidenberg, 2002: 328 y 330).

cuotas, etc. Muy pocas, por el contrario, se establecieron en relación con quién podía ser candidato. Refirámonos a continuación, con más detalle, a lo que prescribían las normas de cada uno de los partidos para la ocasión.

\section{Marco normativo del PSOE}

Tras la celebración del XXXV Congreso del PSOE y de la Conferencia Política de julio de 2001, el procedimiento específico de selección del candidato a la Presidencia del Gobierno quedó expresamente fijado en la Normativa Reguladora de los Cargos Públicos (NRCP), concretamente en el Título II "De la selección de candidatos y candidatas en los diferentes procesos electorales". Aquél debía respetar una serie de principios incluidos en el Título I de la NRCP, al margen de las referencias contenidas en los Estatutos. En primer lugar, el derecho de todo afiliado, militante o no, en pleno uso de sus derechos orgánicos y que dispusiese de la condición de elegible, o de personas independientes propuestas de conformidad con la normativa interna, a ser propuestos o proponerse como candidatos. Con este alto grado de inclusión democrática del procedimiento, se trataba de dar la imagen de un partido abierto al exterior. En la práctica, no obstante, esta posibilidad era harto difícil en función de los requisitos establecidos para optar a la candidatura. En la elección podían participar los militantes inscritos en el Censo Federal de Militantes o los simpatizantes del Partido inscritos en el Censo Federal de Simpatizantes, actualizado y verificado por la Comisión Ejecutiva Federal, previa autorización de la Oficina de Afiliación y Censos y cerrado en la fecha determinada por el órgano competente. ${ }^{11}$ No obstante, tanto los afiliados como los simpatizantes debían tener una antigüedad mínima de seis meses para poder participar

11 Los Estatutos del PSOE distinguían, dentro de la condición de afiliado, la figura del militante y la del simpatizante. 
en la elección. Además, el mayor o menor carácter representativo y el nivel de proyección social de la persona que se eligiese habrían de ser otros dos criterios a considerar. Por último, se proponía el mérito como garantía de la elección del sujeto más capacitado. De cualquier modo, ni representatividad, proyección social y mérito tenían concreción alguna en las normas, con lo que en la práctica no dejaba de ser más una recomendación que una obligación procesal delimitada. Otros dos principios recogidos en el artículo 72 de los Estatutos, como eran la renovación periódica y gradual en el ejercicio de las funciones públicas y el cumplimiento de los principios de democracia paritaria, resultaban aún más difícilmente concretables en relación con el candidato "presidencial".

Más allá de estos criterios generales, el artículo 37 de la NRCP establecía que la selección de candidato a la Presidencia del Gobierno de la Nación se realizaría a través de un procedimiento de primarias, siempre y cuando existiese más de un aspirante a la nominación. ${ }^{12}$ Sin embargo, el mecanismo tan sólo se accionaría previa decisión aprobada por varios órganos colegiados del partido, concretamente siguiendo la propuesta de la Comisión Ejecutiva Federal, por acuerdo del Comité Federal en el que se dejase constancia del plazo para la presentación de candidaturas al proceso interno. Los candidatos a la Presidencia del Gobierno podrían ser propuestos bien por la Comisión Ejecutiva Federal por mayoría, bien por el aval del Comité Federal -sin especificar el número de miembros-o, en último término, por el apoyo del 10\% de los militantes del partido. Estas exigencias suponían un endurecimiento de los requisitos, en comparación con las previstas en el Reglamento de Selección de candidatos y candidatas a cargos públicos aprobado por el Comité Federal del PSOE el 21 de marzo de 1998, en desarrollo de lo previsto en el artículo 75 y en la Disposición Final 1 ${ }^{\mathrm{a}}$, de los Estatutos del XXXIV Congreso. En la antigua normativa, la militancia exigida era del 7\%; se fijaba en un 15\% de sus miembros el apoyo necesario del Comité Federal, al tiempo que se contemplaba al Consejo Territorial como otro de los posibles proponentes. En consecuencia, la nueva formulación reglamentaria aprobada tras el XXXV Congreso, pese al reconocimiento del derecho a concurrir libremente, propuso un modelo en el que los militantes a título individual o cualquier otro ciudadano tenían muy pocas posibilidades de lograr ser candidato sin contar, previamente, con un alto índice de apoyos en la dirección del partido. Esto sólo sería posible para personajes de amplio bagaje intraorganizativo y / o con una relación preferente en el núcleo de dirección de la misma.

Las propuestas de candidaturas, independientemente de la fórmula empleada, se tenían que presentar a la Comisión Federal de Garantías Electorales dentro de un plazo mínimo de quince días y un máximo de veinte. Esta Comisión, tras comprobar el cumplimiento de los requisitos establecidos, quedaba encargada de proclamar a los aspirantes a la candidatura en el proceso electoral interno. Contra el acuerdo de la Comisión, no obstante, cabía la interposición de un recurso ante el mismo órgano en el plazo de cuarenta y ocho horas. En caso de una única candidatura, la Comisión Federal de Garantías Electorales debía

12 No obstante, en el caso de que en ese momento la Presidencia del Gobierno la ostentase un socialista, el citado procedimiento de primarias sólo sería de aplicación obligada previa solicitud de la mayoría del Comité Federal del partido. No se daba esta circunstancia en el momento de proceder a la selección para 2004. 
comunicar la circunstancia a la Comisión Federal de Listas quien, a su vez, dictaminaría un informe favorable para remitirlo a la Ejecutiva Federal. Posteriormente, el Comité Federal sería el encargado de votar y aprobar la candidatura. ${ }^{13}$ En el supuesto de existir más de un candidato, de acuerdo con el artículo 35 q de los Estatutos y 7 u del Reglamento del Comité Federal (RCF), sería este último el responsable de convocar elecciones primarias y aprobar el censo electoral, siempre a propuesta de la Comisión Ejecutiva Federal (artículos 381 del RF y 7 ñ del Reglamento de Funcionamiento de la Comisión Ejecutiva Federal [RFCEF]).

Si se diese el caso, a los candidatos proclamados se les debía facilitar en igualdad de condiciones el desarrollo de las actividades de información interna: comunicación postal con los afiliados y afiliadas, utilización de los locales señalados al efecto para la celebración de reuniones y la presencia en la comunicación interna del partido. De cualquier modo, las actividades informativas que desarrollasen los candidatos, que no podrían durar más que siete días, deberían ajustarse a una serie de reglas dirigidas a limitar el grado y el carácter de las discusiones. Se prohibían, expresamente, las campañas de imagen y la publicidad pagadas o sometidas a algún tipo de contraprestación. Asimismo, quedaban prohibidas las manifestaciones que supusiesen descalificación o menoscabo hacia otras candidaturas, cargos públicos o responsables orgánicos. Para evitar previsibles problemas, el cumplimiento de las pautas de comportamiento en el proceso de primarias quedaba bajo la vigilancia de la Comisión de Garantías Electorales Federal.

El voto en las primarias, de convocarse éstas, era individual y secreto. Los votantes habrían de inscribirse en el censo del partido, acreditando su identidad antes de ejercer el derecho. La NRCP desarrollaba con precisión las pautas a seguir en la votación y posterior recuento, así como los potenciales recursos contra el escrutinio. Una vez finalizado el proceso, la Comisión Federal de Listas dictaminaría y daría traslado a la Comisión Ejecutiva Federal. Ésta, inmediatamente, haría lo propio con el Comité Federal el cual procedería a proclamar al candidato/a definitivo/a.

Pues bien, toda la descripción procesal precedente permite afirmar que el andamiaje normativo en el PSOE pretendía democratizar la selección del candidato en la forma, centralizando su control en la práctica. Así, altos niveles de inclusión tanto por el número de los potenciales candidatos como por los participantes en el proceso de selección, se compatibilizaban con una no disimulada capacidad de control por parte de los órganos del partido -empezando por la exclusividad en la activación del proceso- preocupados por el logro y el mantenimiento de la cohesión interna. 
Gráfico 1: Proceso de selección del candidato presidencial en el PSOE

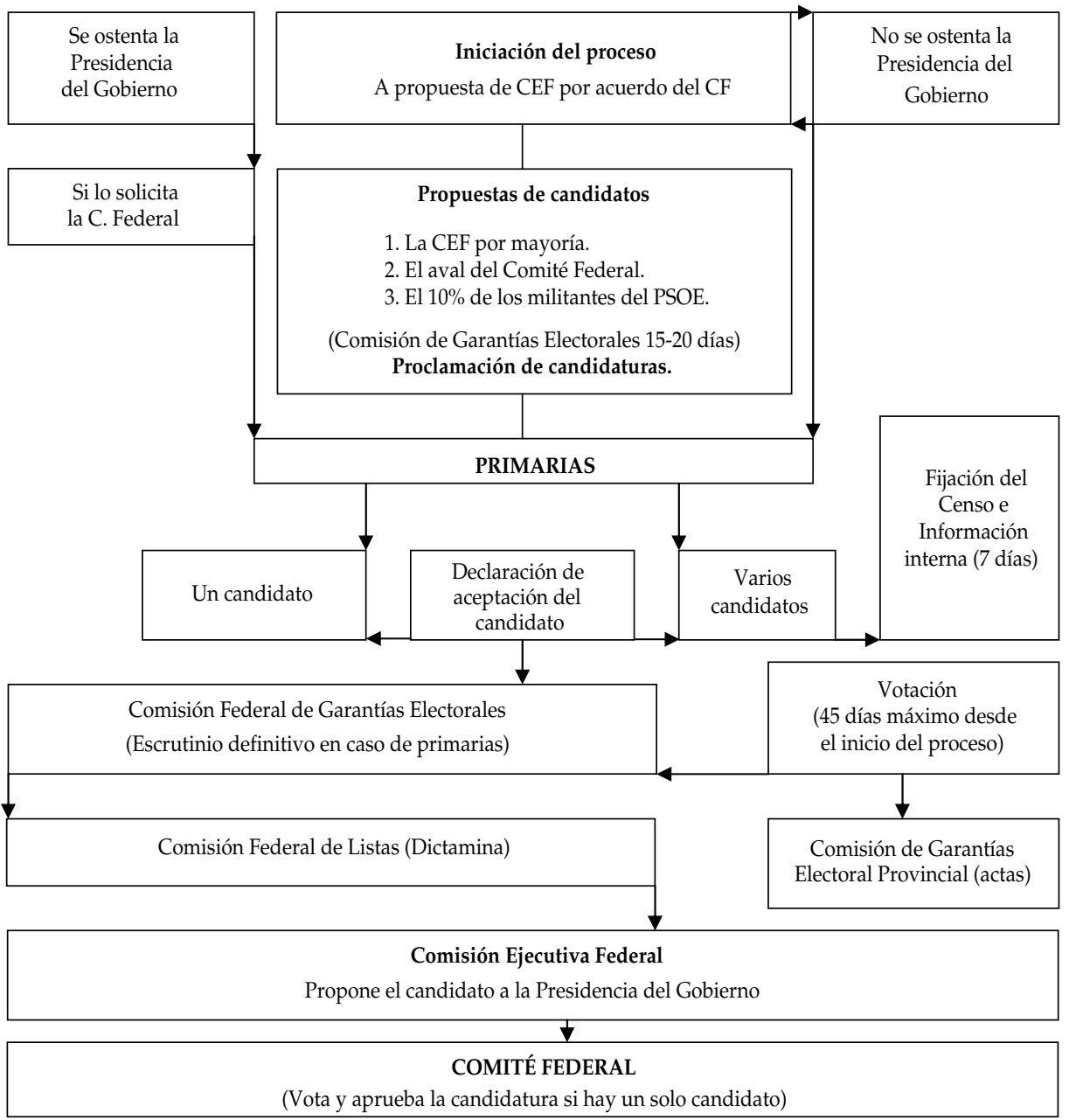

Fuente: Elaboración propia, a partir de los Estatutos y el (NRCP).

\section{Marco normativo del PP}

El PP es una organización que tiene desde su fundación, como una de sus características originales, fuerte presencia del líder y la coalición dominante, lo que le otorga un perfil presidencialista. Como veremos, en manos de ellos y, fundamentalmente del primero, se concentran gran parte los recursos de poder de la organización (Chadel, 2001: 3).

Pese a esta circunstancia, en sus estatutos se contempla una serie de fórmulas orientadas a presentar un funcionamiento formal de naturaleza democrática y participada. Concretamente, y para el momento que nos ocupa, en el apartado g) del artículo 6 de los Estatutos aprobados en el XIV Congreso Nacional del PP celebrado los días 25, 26 y 27 de enero de 2002 se establecía que todo afiliado estaba en disposición de formar parte de cualquiera 
de las candidaturas que el partido presentase en los diferentes procesos electorales. Por consiguiente, es de suponer que esta posibilidad resultaba extensible al caso de la candidatura a la Presidencia del Gobierno. ${ }^{14}$ Nada se decía, en cambio, en relación con la participación activa en los procesos de selección de candidaturas, no especificándose si era competencia exclusiva de afiliados militantes, o cabía la participación de los simpatizantes. Tampoco ningún artículo establecía la obligación de que el candidato designado debiera ser, necesariamente, afiliado del partido. El derecho a ser candidatos de los afiliados no excluía que ésta responsabilidad pudiese recaer sobre alguien desligado orgánicamente del partido, esto es, sobre cualquier ciudadano. Esta circunstancia presentaba al procedimiento formal del PP como de un alto grado de inclusión democrática en la vertiente de la amplitud de los concurrentes potenciales.

En términos generales, lo llamativo es que las normas internas del PP, empezando por sus Estatutos, eran muy exiguas y superficiales en cuanto al proceder para la nominación del candidato presidencial. La única mención expresa que se incluía estaba referida al órgano encargado de designarlo. El artículo 32, apartado segundo, concretamente, otorgaba en exclusiva dicha competencia a la Junta Directiva Nacional. Por tanto, teniendo en cuenta las previsiones sobre el funcionamiento y la toma de decisiones por parte de la mencionada Junta, artículo 20 de los Estatutos, lo único que se podía presuponer era que la designación del presidenciable se haría por la mayoría simple de los algo más de quinientos asistentes potenciales, todos ellos miembros de la dirección orgánica del partido y cargos institucionales o representativos.

Así las cosas, la citada Junta, cuya composición definitiva quedaba cerrada en el Congreso Nacional, resultaba decisiva a la hora de conocer el grado de control del proceso por parte de la dirección y, más en concreto, de su máximo líder. ${ }^{15}$ A éste, el Presidente Nacional, le correspondería, en último término, hacer la propuesta del candidato que la Junta habría de designar tras la aceptación del Comité Ejecutivo Nacional. No obstante, debe insistirse en que sobre la cuestión no había reflejo alguno en los mencionados estatutos. Es ésta, tan sólo, una deducción lógica de la naturaleza de máximo responsable del partido atribuida por el artículo 39 de los Estatutos al Presidente Nacional del PP. ${ }^{16}$

Aunque es de suponer la observancia de ciertas características y cualidades deseables en los candidatos por parte de los órganos encargados de llevar a cabo el proceso, tampoco se recogía previsión alguna al respecto en las normas internas del PP. La mayor o menor idoneidad del candidato propuesto quedaba al albur exclusivo de la persona encarga de proponer a la Junta el nombre del candidato, esto es, el Presidente Nacional del PP, y a las fijadas, en su caso, por la propia Junta.

14 La normativa empleada por el Partido Popular para designar a su candidato a la Presidencia del Gobierno en las elecciones de marzo de 2004 estaba contenida, básicamente, en el texto de los Estatutos aprobados en el XIV Congreso Nacional de la formación.

15 Los elementos variables en la composición de la Junta Nacional eran, entre otros: los miembros del Comité Ejecutivo Nacional, de entre los que cinco personas eran designadas directamente por el Presidente Nacional, así como los veinte vocales elegidos por el propio Congreso.

16 Información basada en los datos aportados en conversación telefónica por Alfonso Serrano, asesor del Área de Organización del PP. 
Gráfico 2: Proceso de selección del candidato presidencial en el PP

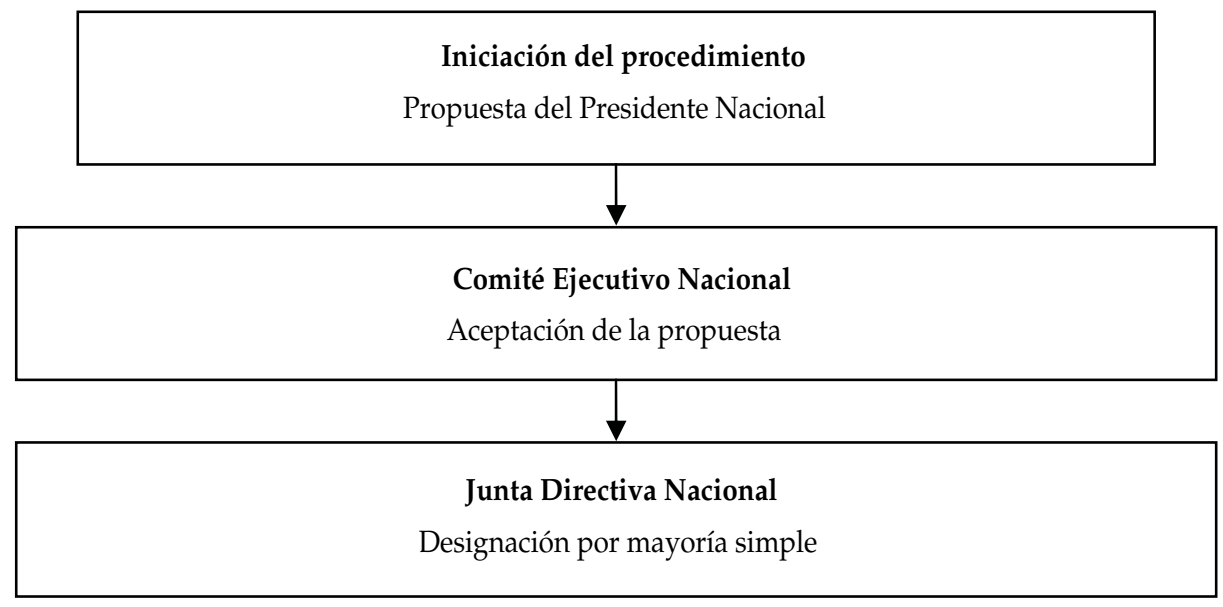

Fuente: Elaboración propia, a partir de los Estatutos aprobados en el XIV Congreso.

En conclusión, el análisis de la normativa interna del PP revela varios extremos. De una parte, que el filtro del líder, a quien se le asignaba la propuesta de candidato, limitaba de entrada el carácter inclusivo del procedimiento, pese a que aquél pudiera elegir a personas ajenas a su propio partido. Por otra, que formalmente se prescindía de la participación de los ciudadanos y de los afiliados, optando de forma abierta por el control del proceso sucesor, mediante la concesión exclusiva de cierto protagonismo a los miembros de la dirección representados en la Junta Directiva Nacional. Sin duda, esta previsión perseguía sostener el alto grado de cohesión interna que había caracterizado hasta el momento al PP en el gobierno.

\section{PROCESOS INFORMALES}

En 2004, la selección de los respectivos candidatos a la Presidencia del Gobierno por el PP y el PSOE se afrontó desde posiciones de partida bien distintas. Así, mientras que los socialistas se vieron forzados a buscar un nuevo líder en un marco interno conflictivo, los populares afrontaron el proceso sucesor desde el poder, cuando el éxito político les sonreía y los resortes de la maquinaria pública estaban a su disposición. En el primer caso se trataba de buscar un líder para consolidar el cambio en la organización socialista y reconstituir su capacidad electoral. Por su parte, la sucesión en el Partido Popular se desarrolló para gestionar la sustitución del líder pero no para la dirección del cambio en la totalidad de la organización política. En definitiva, búsqueda de un nuevo liderazgo en el PSOE; búsqueda de un liderazgo de sustitución en el PP.

Los socialistas, después de varios intentos fallidos, pretendían cerrar el vacío de liderazgo externo. Los populares tan sólo deseaban encontrar una figura de continuidad al liderazgo de Aznar. En congruencia con su diferente naturaleza, mientras que el proceso en el 
seno del PSOE tuvo un recorrido largo, dificultoso y, en cierto modo, traumático para determinados sectores del partido; en el caso del PP, el proceso fue corto, ordenado y previsible en sus consecuencias inmediatas. Además, si tras la elección del nuevo líder socialista las desavenencias internas aún pervivían y la proyección exterior todavía no se había logrado; en el PP, la consolidación interna estaba prácticamente conseguida, mientras que la proyección exterior aparentaba ser una tarea menos dificultosa a tenor de las ventajas que suelen acompañar al ejercicio efectivo del poder público.

\section{Del liderato al liderazgo de José Luis Rodríguez Zapatero}

Rodríguez Zapatero alcanzó la Secretaría general del PSOE en julio de 2000. Se ponía fin a un largo periodo de inestabilidad en el liderazgo socialista inaugurado tras el abandono de Felipe González dos años después de la derrota sufrida en las elecciones generales de 1996. Tras la salida del carismático González, la dirección del PSOE recayó en Joaquín Almunia. ${ }^{17}$ Éste, acompañado por un buen número de veteranos dirigentes del partido intentó relanzar el proyecto socialista y fortalecer su recién estrenado liderazgo, mediante la convocatoria de un procedimiento de primarias para la selección del candidato a la Presidencia del Gobierno (Robles Egea, 2005: 27). En gran medida, la decisión de adoptar elecciones primarias fue una respuesta a consideraciones estratégicas a corto plazo (Hopkin, 2001: 355). Era preciso generar un reequilibrio de la coalición dominante o círculo interno del poder, esto es, del grupo de quienes deberían controlar a partir de ese momento los principales recursos de poder de la organización. ${ }^{18}$ Sin duda, a juzgar por varios indicadores, en un principio, el promotor de la idea parecía haber logrado su objetivo. El Centro de Investigaciones Sociológicas, en su Barómetro de abril, recogía un dato según el cual, el 87,2 \% de los entrevistados había tenido conocimiento del proceso de primarias. ${ }^{19}$ Las primarias se convirtieron en un éxito publicitario, hasta tal punto que la mayor parte de las encuestas mostraba una mayoría de ciudadanos españoles satisfechos con este procedimiento adoptado por el PSOE (Boix, 1998: 36). Pero el efecto se desvaneció rápidamente. Lo que en un principio se ideó con las finalidades de recomponer la coalición dominante, fortalecer el proyecto y al líder, terminó volviéndose en un motivo añadido para prolongar la estancia del PSOE en la oposición.

Contra casi todas las previsiones, José Borrell, ex ministro socialista, se había decidido a concurrir en competencia con el Secretario General, resultando vencedor en el envite e inaugurando una etapa de forzada cohabitación entre la Secretaría General y el candidato a la Presidencia de Gobierno. ${ }^{20}$ En mayo de 1999 la situación cambió bruscamente. Borrel presentó su dimisión tras salir a la luz ciertos casos de enriquecimiento ilícito que afectaban a antiguos colaboradores. Más allá de la existencia de este desencadenante justificador de la dimisión, con el abandono del vencedor de las primarias se escenificó la difícil

Véase sobre los conceptos de coalición dominante y círculo de poder (Panebianco, 1990: 89) y (Duverger, 1987: 181-198).

19 CIS., Barómetro de abril. Estudio 2285.

20 Las primarias se celebraron el 24 de abril de 1998. 
convivencia entre la organización superviviente y el candidato, quien nunca llegó a contar con la lealtad completa de muchos miembros de la dirección socialista. Los conflictos afloraron en más de una oportunidad. ${ }^{21}$

El PSOE había optado por unas "primarias cerradas mixtas" o, lo que es lo mismo, un procedimiento que no tocaba la estructura interna del poder y donde el aparado del partido seguía jugando un papel relevante durante el proceso y, una vez concluido, al lado del candidato seleccionado. Se habían evidenciado, por consiguiente, varios elementos negativos. Por un lado, la polarización de la militancia; por otro, la escasa autonomía real de los candidatos concurrentes y del candidato seleccionado con respecto a la dirección. Los resultados no dejaron lugar a dudas.

Tras la dimisión del ganador de las primarias, Almunia, promotor y perdedor de aquéllas, asumió el testigo dejado por Borrell, convirtiéndose en el candidato a la Presidencia por designación del Comité Federal. Las consecuencias del forzado relevo fueron inmediatas. El PSOE perdió las elecciones y el PP se alzó con la mayoría absoluta. Almunia abandonó la Secretaría General, y una comisión gestora se hizo cargo del PSOE hasta que un congreso extraordinario resolviese el vacío de poder.

El XXXV Congreso se inició el 22 de julio de 2000, y lo hizo con gran incertidumbre respecto a quien asumiría la dirección y el liderato del partido. Tras derrotar a otros tres aspirantes, José Luis Rodríguez Zapatero logró imponerse. ${ }^{22}$ Éste, y pese al escaso margen de votos que le separó de su inmediato perseguidor, José Bono, reforzó el liderato de partida gracias al mayoritario apoyo obtenido por su propuesta de comisión ejecutiva. No obstante, el control del partido y el ejercicio de un liderazgo eficaz aún estaban por demostrar.

En el nuevo escenario abierto una vez cubierta la vacante de la Secretaría General del PSOE, el recuerdo de los nefastos resultados obtenidos por el proceso de primarias empleado para la selección del candidato años antes, trajo como consecuencia el abandono de cualquier interés por hacer un uso real del mismo para designar al nuevo candidato en las elecciones de 2004. El propio Zapatero había afirmado en su discurso de clausura congresual, que el cambio debería ser tranquilo. ${ }^{23} \mathrm{Si}$ bien en la práctica la nueva dirección no se atrevió a clausurar por completo las primarias, lo cierto es que no hizo nada por fomentar el surgimiento de aspirantes alternativos a la candidatura del Secretario General. La citada dirección, por el contrario, cumplió a la perfección con las funciones que tradicionalmente se le asignan: la interpretación del orden normativo interno y la supervisión del proceso de selección, reclutamiento y promoción de dirigentes y líderes políticos (Panabianco, 1990: 90 y ss). De esta forma, pese a la pervivencia del instrumento de selección, la cúpula

21 Especial significación tuvo el conflicto abierto y la disparidad de posiciones, con relación al pacto que el PSOE negoció en Madrid con Nueva Izquierda. Entonces, el candidato socialista propuso compatibilizar un proceso de primarias para elegir al candidato a la Presidencia de la Comunidad de Madrid, con el citado pacto, al tiempo que alertó del peligro de que los enfrentamientos internos acabasen dilapidando el impulso político y la proyección social que el PSOE había cobrado a raíz de la celebración de sus primarias.

22 A la Secretaría General optaron José Bono, Matilde Fernández, Rosa Díez y José Luis Rodríguez Zapatero. La diferencia entre este último y Bono fue de tan sólo ocho votos de los delegados. Obtuvo 414 votos, esto es el $41,7 \%$ de los delegados, frente a los 405 que representaba el 40,8\% de los votos que consiguió José Bono.

23 El discurso está publicado íntegramente en (López Alba, 2002: 442-450). 
hizo valer la superioridad del objetivo de buscar la unidad y la cohesión, aunque ello supusiese limitar la proyección democrática del partido mediante la reducción de los niveles de inclusión.

El 2 de septiembre de 2002, la ejecutiva del PSOE propuso al Comité Federal la apertura del proceso para la elección del candidato, en cumplimiento estricto de las previsiones estatutarias. Cuatro días después, el Comité convocó elecciones primarias, tras lograr Manuel Chaves, presidente del PSOE, el acuerdo de los secretarios generales -baronesde las federaciones en torno a la idoneidad de dicha convocatoria. Entonces, todos ellos estimaron la oportunidad de mantener las primarias como método de elección del aspirante a la Moncloa, en primer lugar porque así lo establecían los artículos 40 al 50 de sus estatutos federales y, en segundo término, porque permitía dejar patente, al menos sobre el papel, las diferencias procesales con respecto a las prácticas del partido del gobierno.

A partir de aquí, todo transcurrió de forma controlada, en tanto que fueron la propia Ejecutiva, con Rodríguez Zapatero a la cabeza, y los dirigentes regionales los encargados de decidir, entre las tres vías posibles, el procedimiento a seguir para la presentación del candidato. Para fomentar una imagen de unidad y cohesión desconocida en los años precedentes, la dirección socialista entendió oportuno que el candidato contara con las tres vías de aval. En especial, la cúpula socialista deseaba lograr un número de militantes significativo que avalase la candidatura del Secretario General. Para ello, incluso, impulsó la constitución de una plataforma con la intención de recabar la firma de cincuenta mil militantes socialistas, pese a que bastaban diez mil. En cualquier caso, más allá de la actuación de la cúpula, lo cierto es que la cercanía de la elección del nuevo líder después de un proceso competitivo en el seno del partido contribuyó, de forma natural, a desincentivar la aparición de candidatos alternativos que hubiese obligado, de haberlos, a la celebración de una contienda electoral interna.

Así las cosas, el día 25 de octubre, transcurrido el plazo de presentación de candidaturas sin que concurriese otra que la del propio Rodríguez Zapatero, el Comité Federal, compuesto por doscientos seis miembros, le proclamó candidato a presidente del Gobierno y, cinco días después, el elegido fue "aclamado" por más de veinticinco mil militantes y simpatizantes socialistas en acto público que se hizo coincidir con la fiesta conmemorativa de la primera victoria electoral del PSOE el 28 de octubre de 1982. Se aunaban de esta manera, deliberadamente, el futuro y la historia.

Pese a la forma interesada y controlada de ordenar el proceso, no obstante, se habían tenido en cuenta los tres criterios incluidos en los Estatutos del PSOE para elegir candidato, esto es: representatividad, proyección social y mérito. El primero, en función de la obtención del máximo respaldo a la candidatura en el seno del partido. La proyección social, estimada en función de la valoración de su liderazgo recogida por varios estudios publicados en fuentes oficiales. ${ }^{24}$ Por último, el mérito, dado que dos años antes Rodríguez Zapatero 
Tabla 2: Criterios de selección del candidato en el PSOE

\begin{tabular}{|l|l|c|c|}
\hline \multirow{7}{*}{ CRITERIOS } & \multicolumn{1}{|c|}{ Representatividad } & Mérito & Proyección social \\
\cline { 2 - 4 } & Logro del triple aval: & - Obtención competitiva & \\
& - Propuesta de la & de la Secretaría General & \\
& Ejecutiva Federal. & del PSOE. & \\
& - Aval del Comité & - Configuración de una & - Alta valoración social \\
& Federal. & ejecutiva con apoyo & de su liderazgo. \\
& - Solicitud de, al & mayoritario. & \\
menos, un 10\% de la & $\begin{array}{l}\text { Logro de cohesión } \\
\text { militancia. }\end{array}$ & \\
\hline
\end{tabular}

Fuente: Elaboración propia.

también había resultado vencedor en un Congreso frente a otros tres candidatos, logrando el apoyo mayoritario a su propuesta de dirección.

A la postre, la combinación atinada de dos dimensiones, la del respeto a los requisitos formales y la del control procesal interno, resultó ser la fórmula más acertada para lograr dos objetivos. De una parte, poner fin a la mayoría de los conflictos internos de partido y, de otra, facilitar la identificación de la mayoría de los militantes y dirigentes con el nuevo líder.

En cualquier caso, una organización fuerte surgida de un congreso facilitó el final feliz, pero redujo las evidencias participativas del proceso selectivo. Si bien no resulta posible cuestionar la naturaleza democrática del proceder, otra cosa es la disminución real del nivel de participación que tuvieron los militantes.

\section{De Aznar a Rajoy: La intrahistoria del proceso sucesor en el Partido Popular}

La designación de Mariano Rajoy como candidato a la Presidencia del Gobierno fue el resultado de una decisión personal. José María Aznar, en su condición de presidente del PP y del Gobierno (1996-2004), asumió la responsabilidad última para fijar el calendario de la sucesión y para seleccionar, entre diversas alternativas, el nombre de quien mejor se ajustaba a sus preferencias. No obstante, el proceso fue "participado" en tanto que el líder escuchó, a título meramente consultivo, el parecer de las principales personalidades políticas del partido.

En rigor, el relevo en el liderazgo se había puesto en marcha ocho años antes, cuando el propio Aznar, adelantándose y dando por supuesta la victoria electoral de 1996, anunció a los medios de comunicación su intención de no permanecer al frente del ejecutivo más de dos legislaturas. Una vez en el gobierno, y durante los cuatro años siguientes, no volvió a mencionar este compromiso. 
La mayoría absoluta lograda en las elecciones de 2000 vino a reforzar la figura de Aznar y apartó, por completo, cualquier tipo de duda en torno a su liderazgo. ${ }^{25}$ Pese a todo, fue entonces cuando de nuevo volvió a surgir la cuestión de la renuncia a continuar a la finalización del recién estrenado mandato. La decisión de no volver a concurrir, según confesión propia, la había adoptado en consecuencia con profundas convicciones y razones personales, convirtiéndose, a la postre, en el principal elemento legitimador del procedimiento personalista a seguir en la fijación del nombre de quien habría de sustituirle.

La fase decisiva del proceso se inauguró en enero de 2002, coincidiendo con el XIV Congreso del PP. Ante los casi tres mil compromisarios presentes en el cónclave de los conservadores, Aznar ratificó su promesa de años antes y dio salida oficiosa a la sucesión, al pronunciarse en los siguientes términos:

"[...] mis queridas amigas y amigos. [...] os presento mi candidatura a la presidencia del PP, por quinta vez. Por quinta vez consecutiva, y quiero deciros que es la última. No habrá otra vez. [...] no sé si realmente puedo pedir que compartáis estas decisiones, que afectan tanto a la futura candidatura a la Presidencia del Gobierno de España como al Partido Popular". ${ }^{26}$

Entonces y después, muy pocos de entre los dirigentes del PP pusieron en duda la licitud de la unilateralidad en la decisión que anunciaban las palabras de Aznar. El secretario general de los populares, Javier Arenas, se encargó de confirmar la esencia caudillista del procedimiento que se habría de poner en marcha una vez que el líder pusiera fin a su segundo mandato: "Tú sabes lo que pensamos y lo que queremos. Tus decisiones las tomarás pensando en el interés de España". ${ }^{27}$ Así, el guión de la sucesión era dictado por Aznar y escrito por Arenas.

El ministro y ex secretario general del Partido Popular, Álvarez Cascos, y el ministro de Defensa, Federico Trillo Figueroa, fueron las dos principales voces "disidentes" respecto del procedimiento a seguir. El primero presentó dos enmiendas a la ponencia de estatutos, concretamente a los artículos 24 y 27. En ellas se solicitaba la limitación de mandatos a un mínimo de ocho años prorrogables a diez si se diese por medio una disolución anticipada de las Cortes y, además, se argumentaba la necesidad de otorgar competencias exclusivas al Congreso del PP para aprobar excepciones a esta regla. Por su parte, Trillo Figueroa, a finales de 2002, recordó públicamente el procedimiento seguido para designar en su día a Aznar presidente del partido y candidato a la Presidencia del Gobierno. Sugirió que la fórmula de sanedrín empleada entonces debería repetirse para fijar el nombre de quien, a su vez, tendría que relevar a Aznar. Entonces, Manuel Fraga consultó a Francisco Álvarez

Cuando Aznar hizo pública su intención de permanecer sólo dos legislaturas al frente del Ejecutivo, tan sólo Alberto Ruiz-Gallardón manifestó, abiertamente, su interés por concurrir a una posible carrera sucesoria. Pese a esta temprana "presentación" de intenciones, Gallardón nunca estuvo en la lista de candidatos potenciales elaborada por Aznar. Véase El Mundo, 4 de mayo de 1999. Mucho más adelante, Rodrigo Rato presentó su candidatura al afirmar que poseía las que a su juicio eran las tres cualidades requeridas para hacerse con el puesto: pasión política, liderazgo e ideología. Véase El País, 24 de enero de 2003.

$27 \quad$ El País, 26 de enero de 2002. 
Cascos, Juan José Lucas, Rodrigo Rato y al propio Federico Trillo sobre la persona idónea para consolidar la refundación del Partido Popular. ${ }^{28}$

En cualquier caso, y al margen de estas pequeñas "disidencias", lo cierto es que Aznar se había encargado de dejar claro a los compromisarios presentes en el Congreso de enero, que era en la cúpula dirigente que saliese del conclave de los populares donde habría que encontrar a las personas con capacidad sobrada de liderazgo para cubrir la vacante (Iglesias, 2003: 123 y ss.). De esta forma, había delimitado el margen de la selección-designación, y había dejado claro que sólo él sería el encargado de proponer el nombre del candidato. El nuevo líder, por consiguiente, habría de salir del círculo de poder interno. Así, desde la tribuna de oradores y uno tras otro, en aquel congreso fue pronunciando el nombre de todos los componentes del Comité Ejecutivo Nacional. Sin referirse expresamente a ellos, quiso dejar constancia de los nombres que más posibilidades tenían de estar presentes en la carrera. Felicitó a Javier Arenas por su labor como coordinador del PP e hizo un elogio público de los currículos y trayectorias políticas de Mariano Rajoy, Rodrigo Rato y Jaime Mayor, entonces vicesecretarios del partido, así como de Ángel Acebes, otro de los nombres que también sonó con cierta insistencia como posible tapado para ocupar la candidatura del PP. Quiso dejar claro, con estas manifestaciones públicas, que fuese cual fuese su decisión, ésta estaría justificada en razón de las cualidades presentes en todos y cada uno de los potenciales candidatos, esto es, en sus currículos. Nada se decía en los estatutos sobre las cualidades ni capacidades que debiera tener el candidato propuesto, pero el líder tenía la obligación de preparar el terreno de su decisión basándola en una lógica meritocrática.

En aquel congreso no se zanjó la cuestión sucesoria, pero sí se compuso el equipo de dirigentes que quedaba encargado de la gestión institucional, de imagen y organizativa, del proceso a seguir. De nuevo, frente al vacío de los Estatutos sobre la cuestión, el líder diseñó el marco y fijó las reglas para la decisión.

Siguiendo su propio guión, unos meses más tarde, en julio de ese mismo año, Aznar acometió una renovación amplia de su gabinete. Con ella, el presidente saliente pretendía ubicar en posiciones estratégicas a los diferentes candidatos potenciales. Entonces, Mariano Rajoy salió bien parado en el reparto de responsabilidades de cara al futuro. Se le apartaba de un ministerio de alto coste político y responsabilidad como el de Interior para asignarle la vicepresidencia primera del Gobierno, fortalecida al asumir las tareas del antiguo ministerio de Presidencia y la portavocía del Ejecutivo. A Rato, por el contrario, pese a continuar en el Gobierno, le relegaba a la vicepresidencia segunda. Además, el parcial "triunfo" de Rajoy quedó patente al conocerse el nombre de algunos de los nuevos ministros, tal fue el caso Ana Pastor, segunda de abordo en Interior, y muy próxima al nuevo titular del citado ministerio, quien pasó a ser Ministra de Sanidad.

28 También, aunque con menor fuerza, expresaron cierta diferencia de parecer uno de los participantes en el cónclave de Perbes (26 de agosto de 1989), Juan José Lucas, y el Presidente fundador, Manuel Fraga Iribarne. Este último, menos explícito, mostró su malestar mediante un interminable reguero de propuestas que entraban en contradicción con la línea política trazada por Aznar después del XIV Congreso. La reforma del Senado, la concesión de mayor protagonismo europeo a las comunidades autónomas, fueron algunas de ellas. 
Más allá de este nuevo marco de poder diseñado por Aznar, en noviembre de 2002, un acontecimiento fortuito, el hundimiento del petrolero Prestige frente a las costas gallegas y la consiguiente catástrofe ecológica que trajo como consecuencia el vertido al mar de miles de toneladas de crudo, propició un escenario de oportunidad para que Rajoy se revelara resolutivo ante Aznar, mostrándose como alguien capaz de mantener el tipo ante de las dificultades y salir prácticamente indemne de la situación.

Sería poco menos de un año después cuando, concretamente en agosto de 2003, el líder del PP se decantó definitivamente por Rajoy, sin hacerlo público en principio, ni siquiera al interesado. Sin criterios establecidos formalmente para decidir sobre los mejores currículos, varias razones pudieron pesar en la decisión final, todas ellas especialmente referidas al mantenimiento de la fuerte cohesión interna que había caracterizado hasta el momento al PP. Por un lado, un perfil experimentado en la brega política, con un alto nivel de conocimiento y valoración tanto dentro como fuera del partido; el mencionado caso Prestige era buena prueba de ello. En segundo término, fidelidad al legado político e ideológico del propio Aznar y, por último, la garantía de continuidad de los integrantes de su equipo político. ${ }^{29}$

Tabla 3: Criterios de selección del candidato en el PP

\begin{tabular}{|c|c|c|c|c|c|c|c|c|}
\hline CRITERIOS & \multicolumn{2}{|c|}{$\begin{array}{l}\text { Experiencia de } \\
\text { gobierno }\end{array}$} & \multicolumn{2}{|c|}{$\begin{array}{c}\text { Proyección interior } \\
\text { y exterior }\end{array}$} & \multicolumn{2}{|c|}{$\begin{array}{l}\text { Fidelidad } \\
\text { al legado }\end{array}$} & \multicolumn{2}{|c|}{$\begin{array}{c}\text { Continuidad del } \\
\text { equipo }\end{array}$} \\
\hline \multirow{4}{*}{$\begin{array}{l}\text { Graduación } \\
\text { descendente }\end{array}$} & $1^{o}$ & $\begin{array}{l}\text { Rajoy } \\
\text { Rato } \\
\text { Mayor }\end{array}$ & $1^{o}$ & $\begin{array}{c}\text { Rato } \\
\text { (Equilibrio) } \\
\text { Rajoy } \\
\text { (Equilibrio) }\end{array}$ & $1^{o}$ & Rajoy & $1^{o}$ & Rajoy \\
\hline & $2^{\circ}$ & Arenas & $2^{\circ}$ & $\begin{array}{c}\text { Mayor } \\
\text { (Exterior) }\end{array}$ & \multirow{3}{*}{$2^{\circ}$} & Arenas & \multirow{3}{*}{$2^{\circ}$} & \multirow{3}{*}{$\begin{array}{c}\text { Arenas } \\
\text { Acebes } \\
\text { Mayor } \\
\text { Rato }\end{array}$} \\
\hline & \multirow{2}{*}{$3^{\circ}$} & \multirow{2}{*}{ Acebes } & $3^{\circ}$ & $\begin{array}{c}\text { Arenas } \\
\text { (Interior) } \\
\end{array}$ & & $\begin{array}{l}\text { Mayor } \\
\text { Acebes }\end{array}$ & & \\
\hline & & & $4^{o}$ & $\begin{array}{c}\text { Acebes } \\
\text { (Interior) }\end{array}$ & & Rato & & \\
\hline
\end{tabular}

Fuente: Elaboración propia.

La experiencia política de gobierno, muy similar entre todos los aspirantes, no podía ser un elemento decisivo, pese a ser un factor imprescindible. ${ }^{30}$ Rajoy, no obstante, sí parecía

29 Otras fuentes añaden a las citadas condiciones mínimas, estar en la dirección del PP y tener experiencia, concretamente en el Gobierno (De la Hoz, 2002: 12).

30 Tanto Mariano Rajoy como Rodrigo Rato habían sido miembros de los sucesivos gobiernos de Aznar desde que el 6 de mayo de 1996 se constituyera el primer gabinete popular. Jaime Mayor había permanecido en el Ejecutivo hasta el 28 de febrero de 2001, justo antes de ser nominado candidato a Lendakari. Javier Arenas, por su parte, había formado parte del primer gobierno, desde 6 de mayo de 1996 al 20 de enero de 1999. Por 
ser el único capaz de sostener la paz interna en el PP, al garantizar la continuidad de los equipos de Aznar. Rato, por el contrario, tenía su propio equipo y un proyecto político personal, de tal manera que era muy probable que, de ser elegido, el segundo nivel del escalafón político en el gobierno se viese trastocado en el futuro inmediato. Mayor Oreja, antiguo militante de la Unión de Centro Democrático (UCD), contaba también con su propio grupo de apoyo, y la continuidad de equipos no quedaba salvaguardada por completo. Por su parte, Arenas y Acebes resultaban, como en el caso de Rajoy, dos garantías de continuidad. En cuanto a las proyecciones interior y exterior de los pretendientes, estaban presentes con distinto peso en cada uno de ellos. Así, Rato contaba con la predilección de las bases, pero despertaba cierto recelo en parte de la opinión pública, tras el escándalo de Gescartera. ${ }^{31}$ Mayor Oreja, gracias a su paso por el ministerio del Interior, había logrado unos fuertes índices de popularidad entre la ciudadanía, favor con el que no contaba entre todos los militantes del partido; además, como Arenas en Andalucía, no había logrado superar con éxito el envite electoral de 2001 en el País Vasco. ${ }^{32}$ El propio Javier Arenas y, a mucha distancia, Ángel Acebes, pasaban por ser los dos líderes menos valorados por los ciudadanos como posibles sucesores de Aznar. En cuanto a la proyección en el interior del PP, Arenas provocaba recelos en el sector de seguidores de Álvarez Cascos, y Acebes era una persona con proyección, pero aún con escaso bagaje interno. ${ }^{33}$ Por su parte, Rajoy resultaba ser el que gozaba de un mayor equilibrio entre sus proyecciones interna y externa. ${ }^{34}$ Aunque el menos valorado en las encuestas de entre los tres grandes aspirantes poseía el perfil más equilibrado en el conjunto de las facetas a considerar. Como consecuencia de todos estos datos, Rajoy se destacó por ser quien menos se alejaba de los criterios fijados por el líder saliente.

Asimismo, el 29 de agosto, Aznar mantuvo un largo encuentro con Rajoy sin darle ninguna pista sobre lo decidido. Esta circunstancia tan sólo se produciría al día siguiente, vía telefónica. "Mariano, te ha tocado" (Iglesias, 2003: 14) y (Diego, 2004: 321). Inmediatamente después de decidirse por el nombre de Rajoy, estableció un calendario para el desarrollo formal del proceso de designación y ordenó la publicidad de las actuaciones y de las fechas previstas para las mismas. Tras consejo de ministros, solicitó al Secretario General del partido la convocatoria del Comité Ejecutivo Nacional. A continuación, programó una

último, Ángel Acebes se convirtió en ministro en la segunda legislatura del PP (Ministro de Administraciones Públicas desde enero de 1999 hasta marzo de 2000, Ministro de Justicia desde marzo de 2000 hasta julio de 2002) y Ministro del Interior desde el 9 de julio de 2002, donde permanecía cuando se inició el proceso de sucesión).

31 Hace referencia a la estafa financiera protagonizada por la agencia de valores Gescartera en 2001. Tuvo repercusiones políticas y judiciales, viéndose obligados a dimitir, entre otros, el secretario de Estado de Hacienda, Enrique Giménez-Reyna, y la presidenta de la Comisión Nacional del Mercado de Valores, Pilar Valiente.

32 Javier Arenas no había logrado ganar las elecciones autonómicas en Andalucía del 3 de marzo de 1996, como tampoco lo había hecho dos años antes, en junio de 1994.

33 Ángel Acebes había sido Alcalde de Ávila desde 1991 a 1995 y ministro desde 1999. En el seno del partido, al máximo nivel, había desempeñado la responsabilidad de Coordinador General del PP.

34 En el Barómetro de enero de 2002, ante la pregunta: Si no se presentara Aznar en las próximas elecciones, ¿quién cree Ud. que sería el mejor candidato del PP?, los encuestados otorgaban a Mayor Oreja el 6,4\% (N: 160), a Rato el 5,6\% (N: 139), a Rajoy, el 5,4\% (N: 135), a Javier Arenas el 3,5\% (N: 88) y, por último, a Ángel Acebes, un $0,2 \%(\mathrm{~N}: 5)$. Total N: 2498. 
serie de consultas con un número considerable de dirigentes de su partido para sondear la opinión de estos sobre la cuestión sucesoria. No obstante, el contenido de las conversaciones no pasó nunca de una solicitud expresa por parte del Presidente de apoyo a la propuesta que haría pública días después. En ningún caso se trató de solicitar preferencias, sino tan sólo de demandar lealtades y apoyos a una decisión ya tomada. La resolución final se hizo pública tras un almuerzo al que el Presidente Nacional del partido convocó a los tres vicesecretarios generales: Rato, Mayor Oreja y el propio Rajoy (Iglesias, 2003: 22 y ss.). Ni tan siquiera las especulaciones periodísticas, provocadas por el propio Aznar, que venían apuntando desde hacía tiempo y de manera clara a la figura de Rajoy, habían sido capaces de alterar los plazos fijados por el Presidente para transmitir la noticia definitiva. Todo se desarrolló según el calendario que él mismo había trazado.

Un acto de legitimación personal del elegido, articulado mediante la celebración de una votación secreta en la Junta Directiva Nacional, integrada por todos los diputados, senadores, presidentes de comunidad autónoma, líderes regionales y provinciales, etc. puso punto y final al procedimiento. El resultado, revelador. De los quinientos cuatro miembros presentes, tan sólo uno se abstuvo, es de suponer que el propio designado.

\section{CONCLUSIONES}

La presidencialización del sistema político español ha propiciado la aparición de un campo de interés en el seno de los partidos relativo a los procesos de selección de candidatos a la Presidencia del Gobierno. Todos ellos han ido incorporando, con mayor o menor precisión, reglas formales en las que se determinan los pasos a seguir para fijar el nombre del que será candidato o candidata.

Los dos grandes partidos españoles, el PSOE y el PP, emplearon fórmulas distintas para acordar el nombre de sus candidatos a la Presidencia en las elecciones generales de 2004. Los socialistas, pese a prever un procedimiento de primarias cerradas, inclusivo tanto por los potenciales candidatos como por los participantes en la selección, optaron por preservar la estabilidad del liderazgo logrado tras varios años de vacío, mediante la articulación de un fuerte control desde la cúpula de la organización. El proceso real fue diseñado desde la Ejecutiva Federal, con el acuerdo del Comité Federal, órgano donde estaban presentes los barones territoriales. Estos últimos emplearon esta oportunidad para reivindicarse como árbitros decisivos en el seno del partido. Ambos, Ejecutiva y Comité, impulsaron la convocatoria de unas primarias, al tiempo que patrocinaron el logro del triple aval previsto estatutariamente para la presentación de candidatura, esto es: propuesta de la Ejecutiva, aval del 10\% de la militancia y propuesta del Comité Federal. La presentación de una propuesta fuertemente respaldada desincentivó la concurrencia de candidatos alternativos al Secretario General. Lograron evitar así la fase más conflictiva de las mencionadas primarias, tal cual era la potencial disputa electoral interna. Por su parte, los populares, que afrontaron el proceso desde el poder, dejaron la decisión a la voluntad exclusiva de su líder. Esta fórmula implicaba un bajo nivel de inclusión democrática en cuanto a los participantes. Bien es cierto, no obstante, que la designación unilateral se 
adornó, gracias a la concurrencia no formal pero implícita de varios candidatos, y a lo previsto en las normas estatutarias, esto es, la decisión de la Junta Directiva Nacional. Uno y otro extremo vinieron a ampliar la apariencia de inclusión.

Sea como fuere, en consonancia con los procedimientos empleados por los dos partidos, quienes tuvieron la última palabra en la selección del candidato consideraron criterios diferentes. El PSOE, a través de su Ejecutiva y de su Comité Federal, optó por la representatividad, el mérito y la proyección social del seleccionado, mientras que el PP, según el juicio cuasi-exclusivo de su líder, lo hizo por la experiencia de gobierno, la proyección interior y exterior, la fidelidad al legado y la continuidad de los equipos de la dirección saliente.

En conclusión, la comparación de los aspectos formales y el desarrollo real de los procedimientos seguidos para la designación de los candidatos en el PP y el PSOE, nos permite afirmar que, pese a prever formas distintas de proceder y de emplear criterios diversos, en ambos casos se dio un bajo nivel real de inclusión democrática. Para preservar la cohesión interna y fortalecer el liderazgo de los partidos, se optó por el centralismo en la toma de decisiones, por la eliminación de una competencia efectiva entre candidatos y por la reducción del número de los participantes en la elección-designación.

\section{REFERENCIAS}

Almunia, Joaquín. 2001. Memorias políticas. Madrid: Aguilar.

Baón, Rogelio. 2001. Historia del Partido Popular: del franquismo a la refundación. Madrid: Ibersaf.

Barrat i Esteve, Jordi. 1995. "Los procesos de selección de candidatos en los partidos políticos". Cuadernos de la Cátedra Fadrique Furió Cerio 13: 95-142.

Boix, Carles. 1998. "Elecciones primarias en el PSOE. Ventajas, ambigüedades y riesgos". Claves de la Razón Práctica 83: 34-42.

Chadel, Frédérique. 2001. “Penser le changement dans les partis politiques. Le processus d'institutionnalisation au Partido Popular". WP, Institut de Ciències Politiques i Socials 192: 1-32.

Dahl, Robert. 1999. La democracia. Una guía para los ciudadanos. Madrid: Taurus.

De la Hoz, Cristina. 2002. Pacto de caballeros. Las claves de la sucesión de Aznar. Barcelona: Belacqua.

Diego Villagrán, Enrique de. 2004. Pretorianos: de dónde vienen y adónde van los fontaneros de la Monclo. Madrid: Martínez Roca.

Duverger, Maurice. 1987. Los partidos políticos. México: FCE.

Freidenberg, Flavia y Francisco Sánchez. 2002. “¿Cómo se elige un candidato a presidente? Reglas y prácticas en los partidos políticos de América Latina". Revista de Estudios Políticos 118: 321-361.

Gallagher, Michael y Michael Marsch (eds.). 1988. Candidate Selection in Comparative Perspective: the Secret garden of Politics. London: Sage.

Hazan, Reuven y Gideon Rahat. 2006. "Candidate Selection: Methods and Consequences". En Handbook of Party Politics, editado por R. Katz y W. Crotty. London: Sage, 109-122.

Hopkin, Jonathan. 2001. "Bringing the Members Back in? Democratizing Candidate Selection in Britain and Spain". Party politics 7(3): 343-361.

Iglesias, Magis. 2003. La sucesión: la historia de cómo Aznar eligió a Mariano Rajoy. Madrid: Temas de Hoy. Jiménez Losantos, Federico. 2004. El adiós de Aznar. Barcelona: Planeta.

Katz, Richard. 2001. "The Problem of Candidate Selection, and Models of Party Democracy". Party Politics 7(3): 277-296.

López Alba, Gonzalo. 2002. El relevo. Crónica del camino hacia el II Suresnes del PSOE 1996-2000. Madrid: Taurus. 
Manin, Bernart. 1992. La democracia del moderni. Milano: Anabasi.

Montabes Pereira, Juan. 2001. "El Gobierno". En Política y Gobierno en España, editado por M. Alcántara y M. A. Martínez. Valencia: Tirant lo Blanc, 172-174.

Palomo, Graciano. 2006. De Aznar a Rajoy (1990-2007): la maldición de Casandra. Los secretos de la derecha española. Madrid: Foca.

Panebianco, Angelo. 1990. Modelos de Partido. Madrid: Alianza.

Pennings, Paul y Rauven Hazan, et al. 2001. "Democratizing Candidate Selection: Causes and Consequences". Party Politics 7(3): 267-275.

Rahat, Gideon y Reuven Hazan. 2001. "Candidate Selection Methods: an Analytical Framework". Party Politics 7(3): 297-323.

Robles Egea, Antonio. 2005. "Líderes, partidos y seguidores. Las redes de apoyo partidista". En Los liderazgos en el mercado político y la gestión pública, editado por A. Natera y F. J. Vanaclocha. Madrid: Universidad Carlos III. Boletín Oficial del Estado.

Salazar Benítez, Octavio. 2000. "Las primarias socialistas: una experiencia de democratización en la selección de candidatos". Teoría y Realidad Constitucional 6 ( $2^{\circ}$ semestre): 135-162.

Vargas-Machuca, Ramón. 1998. "A vueltas con las primarias del PSOE: ¿por qué cambian los partidos?". Claves de la Razón Práctica 86: 11-21.

Santiago Delgado Fernández es Doctor en Ciencias Políticas y de la Administración. Profesor de la Facultad de Ciencias Políticas. Vicedecano de Extensión Universitaria de la Facultad de Ciencias Políticas y Sociología (Universidad de Granada). Ha publicado: El Futuro del Sindicalismo (Diputación de Granada, Granada, 1996), Conceptos fundamentales de Ciencia Política (Alianza, Madrid, 1998). "Sobre el concepto y el estudio del liderazgo político. Una propuesta de síntesis", en Revista de Psicología política. F. "Fernández Ordóñez: un proyecto político para la España necesaria" en J. Cazorla Instituciones políticas (CIS, Madrid, 2005) y Francisco Fernández Ordóñez: un político para la España necesaria (Biblioteca Nueva, Madrid, 2007).

(E-mail: sdelgado@ugr.es) 